\title{
Edificio del Centro Pompidou, París: \\ Un derroche de tecnología o una pieza maestra de arquitectura
}

\author{
The Centre Pompidou building in París: \\ A waste of technology or a masterpiece of architecture
}

DOI: 10.17981/mod.arq.cuc.24.1.2020.03

Artículo. Fecha de Recepción: 15/12/2019. Fecha de Aceptación: 10/01/2020.

Benny Edelberto Danies Echeverria

Universidad Autónoma del Caribe, Barranquilla (Colombia)

bennybeto@yahoo.com

Para citar este artículo:

Damies, B. (2020). Edificio del Centro Pompidou, París: Un derroche de tecnología o una pieza maestra de arquitectura MODULO ARQUITECTURA CUC, no. 24, pp. 49-66, 2020. DOI: http://doi. org/10.17981/mod.arq.cuc.24.1.2020.03

\section{Resumen}

Al observar toda la dinámica actual del edificio del centro Georges Pompidou, su relación con la ciudad de París, su estética maquinisista y el desarrollo de la arquitectura contemporánea, surge la pregunta acerca del diseño de edificios icónicos como ensayos formales, y si estos son una respuesta sensata o coherente al entorno circundante o solo son elementos que contribuyen a una experiencia estética personal. A raíz de este cuestionamiento, este artículo tiene como objetivo analizar su estética, la relación con su entorno circundante y el sentido experiencial del edificio diseñado por los arquitectos Renzo Piano y Richard Rogers en el centro de París, haciendo énfasis en el concepto arquitectónico del primero. El análisis se enfoca en las características físicas, sensoriales y espaciales de este edificio y como estas características hacen de este edificio uno de los más visitados en todo el mundo, iniciando con las dimensiones, el programa y su implantación. Destacando las fortalezas y debilidades del edificio y de cierta manera logra concluir como este proyecto contribuye de forma positiva al desarrollo y evolución de la arquitectura.

Palabras clave: Centro Pompidou; Flexibilidad; Estética; Estilo maquinisista; Contesto urbano

\section{Abstract}

When observing all the current dynamics of the Georges Pompidou Centre building, its relationship with the city of Paris, its machinistic aesthetics and the development of contemporary architecture, the question arises about the design of iconic buildings as formal essays, and whether these are a sensible or coherent response to the surrounding environment or are just elements that contribute to a personal aesthetic experience. Following this questioning, this article aims to analyse their aesthetics, the relationship with their surrounding environment and the experiential sense of the building designed by architects Renzo Piano and Richard Rogers in central Paris, emphasising the architectural concept of the former. The analysis focuses on the physical, sensory and spatial characteristics of this building and how these characteristics make this building one of the most visited in the world, starting with the dimensions, the program and its implementation. Highlighting the strengths and weaknesses of the building and somehow manages to conclude how this project contributes positively to the development and evolution of architecture. Keywords: Centre Pompidou; Flexibility; Aesthetic; Machinisit style; urban context

(c) The author; licensee Universidad de la Costa - CUC. 


\section{INTRODUCCIÓN}

El centro Georges Pompidou es conocido también como el Beaubourg debido al sitio especifico que ocupa en Les Halles, barrio antiguo de París. Inaugurado el 31 de enero de 1977 lleva el nombre del presidente Georges Pompidou, quien fue el gran promotor del proyecto. El presidente Pompidou gestionó que se convocara un concurso internacional de diseño por intermedio del Ministerio de Cultura en 1971 para la creación de un nuevo centro cultural, con un programa arquitectónico amplio que incluía una biblioteca pública, un museo moderno, un centro de diseño industrial y un nodo de investigación artística musical. De igual manera debería incluir espacios para el disfrute y el ocio como cines, librerías y restaurantes. El objetivo era crear una miniciudad cultural para el encuentro de las artes contemporáneas. Se presentaron 681 proyectos de distintos países y la propuesta escogida por el jurado era la de los dos arquitectos Renzo Piano y Richard Rogers, los cuales hasta el momento no eran muy conocidos internacionalmente ni tenían muchos proyectos construidos. Cabe anotar que dos de los jurados que influyeron notablemente en la escogencia fueron el ingeniero Jean Prouvé y al arquitecto Phillip Johnson (Domínguez, 2017). El Centro Georges Pompidou es una obra importantísima para la trayectoria de Piano y Rogers, así como para la arquitectura de esa época, fue algo osado y muy discutido. El mismo Renzo Piano afirmó que habían concebido un edificio descarado y que en cierto momento llego a lamentar su imagen que podría quitarle relevancia a su verdadera esencia y funcionamiento (Jodidio, 2016). Desde el inicio la intención era concebir un edificio, que se lograra compenetrar con el espacio público, prácticamente fuera parte del espacio público mediante la plaza frente a él, respondiendo a prioridades locales. El sitio se convirtió en un símbolo de significado expresivo y en una herramienta activa de la dinámica urbana y social de París. Richard Rogers y Renzo Piano, argumentaban que su proyecto era una nueva ágora cultural para la ciudad de París. Un concepto que se logra apreciar por medio de la organización espacial, la relación con la plaza también propuesta por los arquitectos que gracias a sus dimensiones considerables permite libres circulaciones de público pedestre y la imagen de arquitectura futurista, elementos que materializaban la idea de ágora (Navarrete, 2017).

El mismo Navarrete (2017) comenta:

La plaza se articula con el lobby del espacio interior del primer nivel del edificio que pone en un primer contacto, de manera gratuita, algunas obras temporales y performances para los visitantes. Otro elemento clave de los objetivos institucionales del Centro Pompidou es la BPI, localizada en el segundo y tercer nivel del edificio, con un acceso directo e independiente por la calle Beaubourg, la parte trasera a la plaza principal. La frecuentación de sus salas de lectura es siempre alta y recibe ante todo un público local diverso: estudiantes de diferentes niveles, artistas, investigadores, obreros, empleados, desempleados y personas sin hogar ( $\mathrm{p}$. 169). 
El edificio está diseñado con una organización espacial divida en dos. En una de las partes están agrupados tres niveles de servicios locales y tecnológicos, en la otra parte se encuentra una superestructura de acero y vidrio de siete niveles. Esta superestructura está compuesta por grandes espacios interiores adaptables y en el exterior un entretejido de tuberías y marcos metálicos que revestían todo el contenedor y que hacen parte de toda la red de ventilación, refrigeración, redes eléctricas y demás sistemas. Los pasillos, escaleras y rampas también son externos y bordean una de las fachadas, sin embargo, todo este sistema de circulaciones recibió críticas por ser antiguo comparado con el resto del museo (Brizotti, 2011). El edificio del centro Georges Pompidou se asemeja a un contenedor de 60 metros por 170 metros con capacidad de albergar $7500 \mathrm{~m}^{2}$ de espacios libres en cada una de sus plantas. El arquitecto Renzo Piano expresó que el edificio es extremadamente sencillo de leer, parecido a un diagrama técnico en el cual todo lo que no debería verse, se ve a simple vista tanto así que los visitantes intuitivamente captan la ubicación de los accesos (Barbosky, 2002). La flexibilidad del edificio es una de sus grandes características, y nace a partir del uso de repetitivo de la planta libre y aunque se aspecto maquinisista y tecnológico predominan la realidad es que el edificio fue el resultado de un gran número de piezas hechas a la medida y a mano por técnicos y artesanos (Barbosky, 2002). Cabe resaltar que los proyectos posteriores de Piano Y Rogers efectivamente están muy relacionados con conceptos de flexibilidad y movimiento, con estructuras extremadamente flexibles y prefabricadas con materiales novedosos (Moruno, 2019). Por lo general la colaboración de estos dos arquitectos con grandes y destacados ingenieros ha sido exitosa y constante y en realidad fue la empresa Ove Arup los convidó a participar en el concurso del Centro Georges Pompidou ofreciéndoles 300 libras para trabajar juntos. Los ingenieros Peter Rice y Tom Barker, especialistas en estructuras e instalaciones respectivamente, estaban en esa reconocida empresa y ayudaron en la conceptualización del proyecto y fueron un gran apoyo para Piano y Rogers, tanto así que Piano no ha dejado de colaborar con ellos desde entonces. Estos dos arquitectos siempre han querido utilizar la tecnología más avanzada para crear espacios amables y agradables para la vida sin importar la imagen y cualidad industrial de sus obras, que al final terminan siendo obras de artesanía, pero no artesianas de piedra y ladrillo sino con la utilización de nuevos materiales y soluciones constructivas que se inspiran en lo natural (Sainz, 1990). 
Figura 1. Centro Georges

Pompidou (París, Francia).

Fuente: Foto Mauricio Cabas (2016)

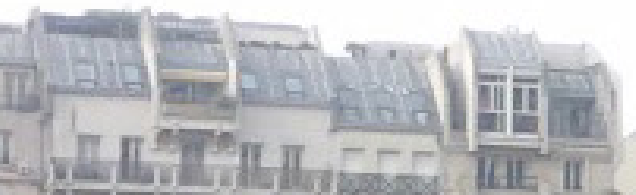

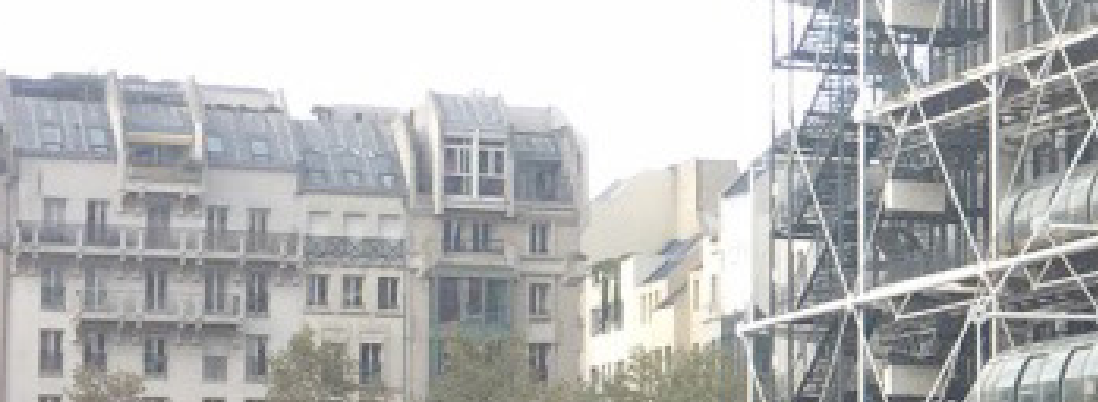
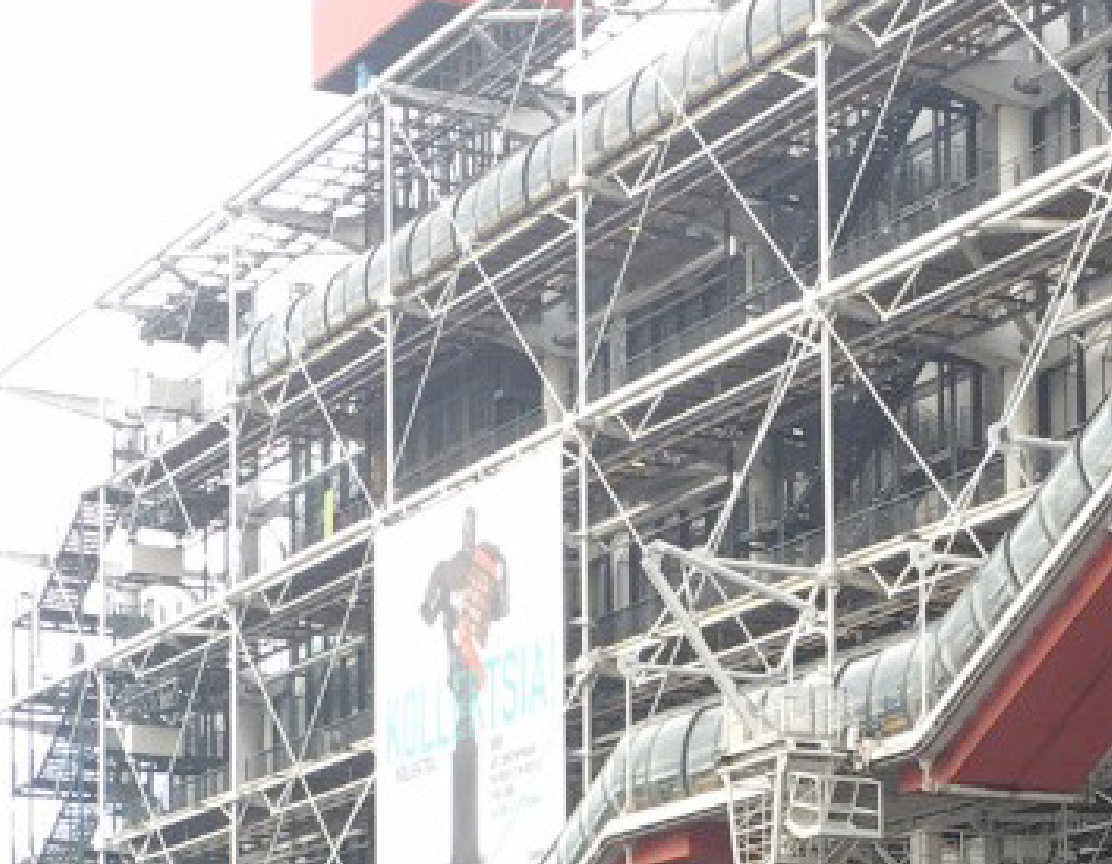

ais Aferis
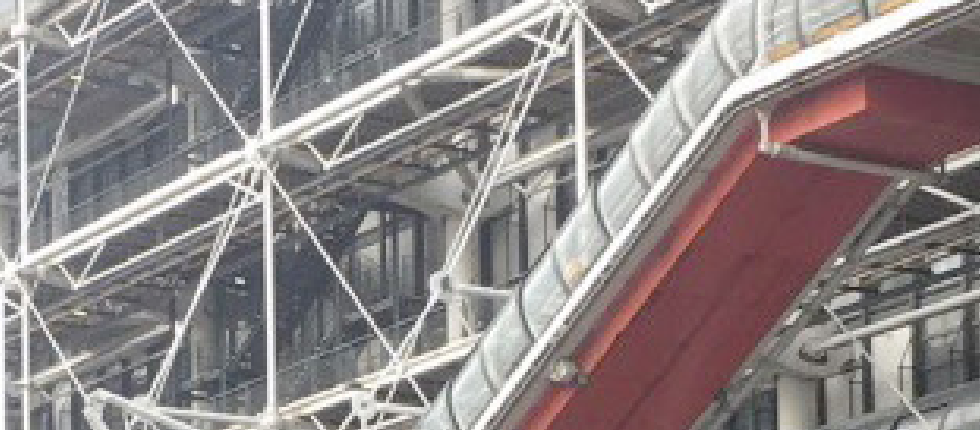

$37+10$

28

238
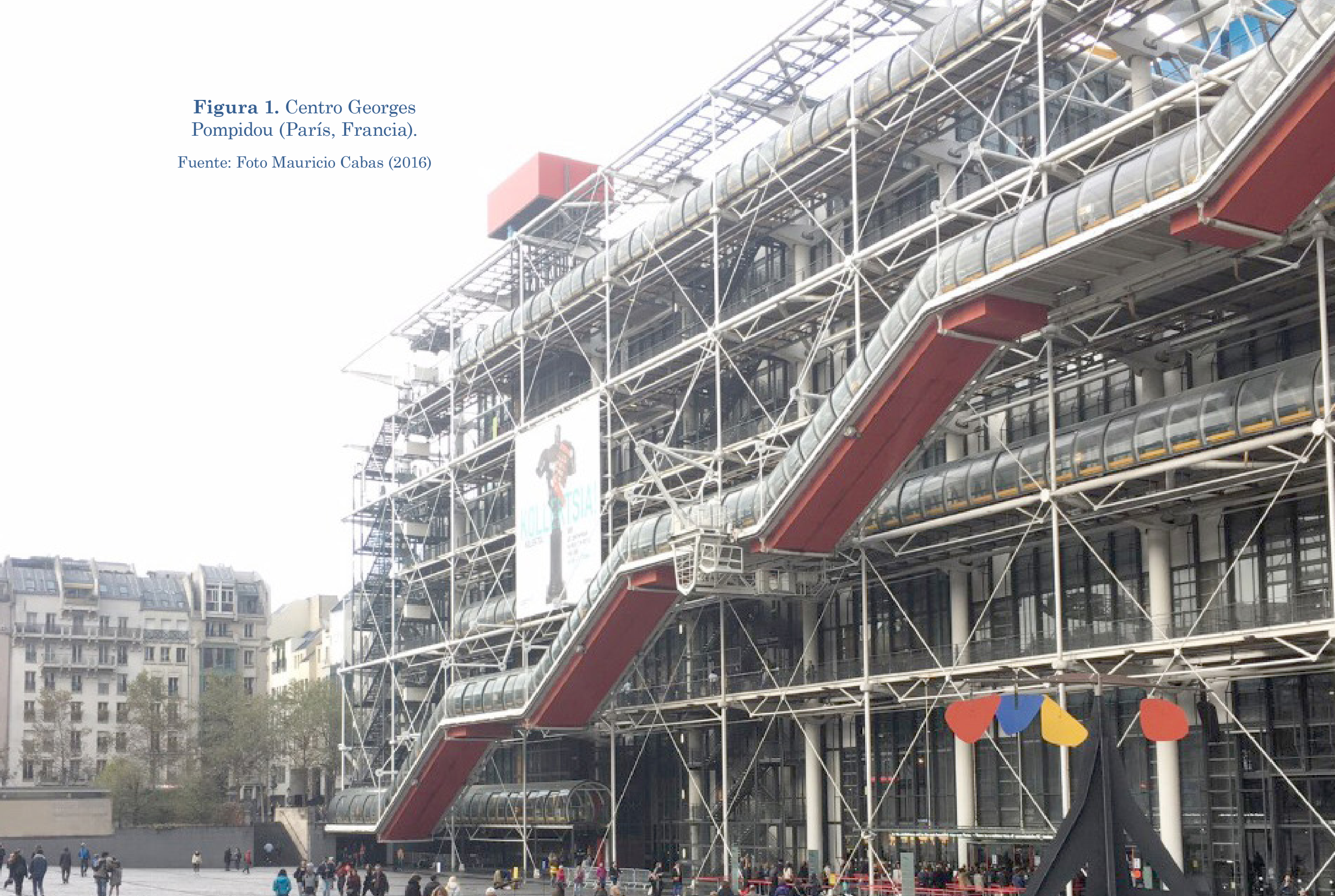

$\pi$.
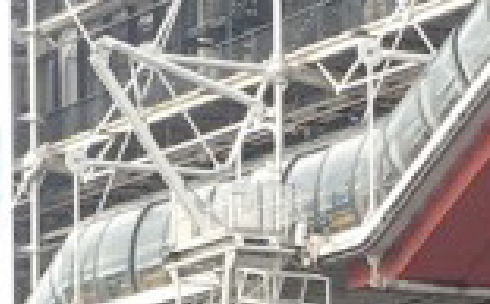

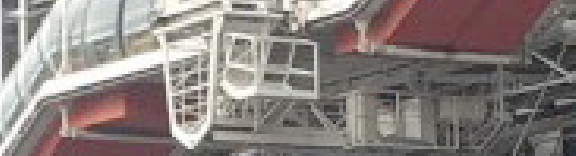
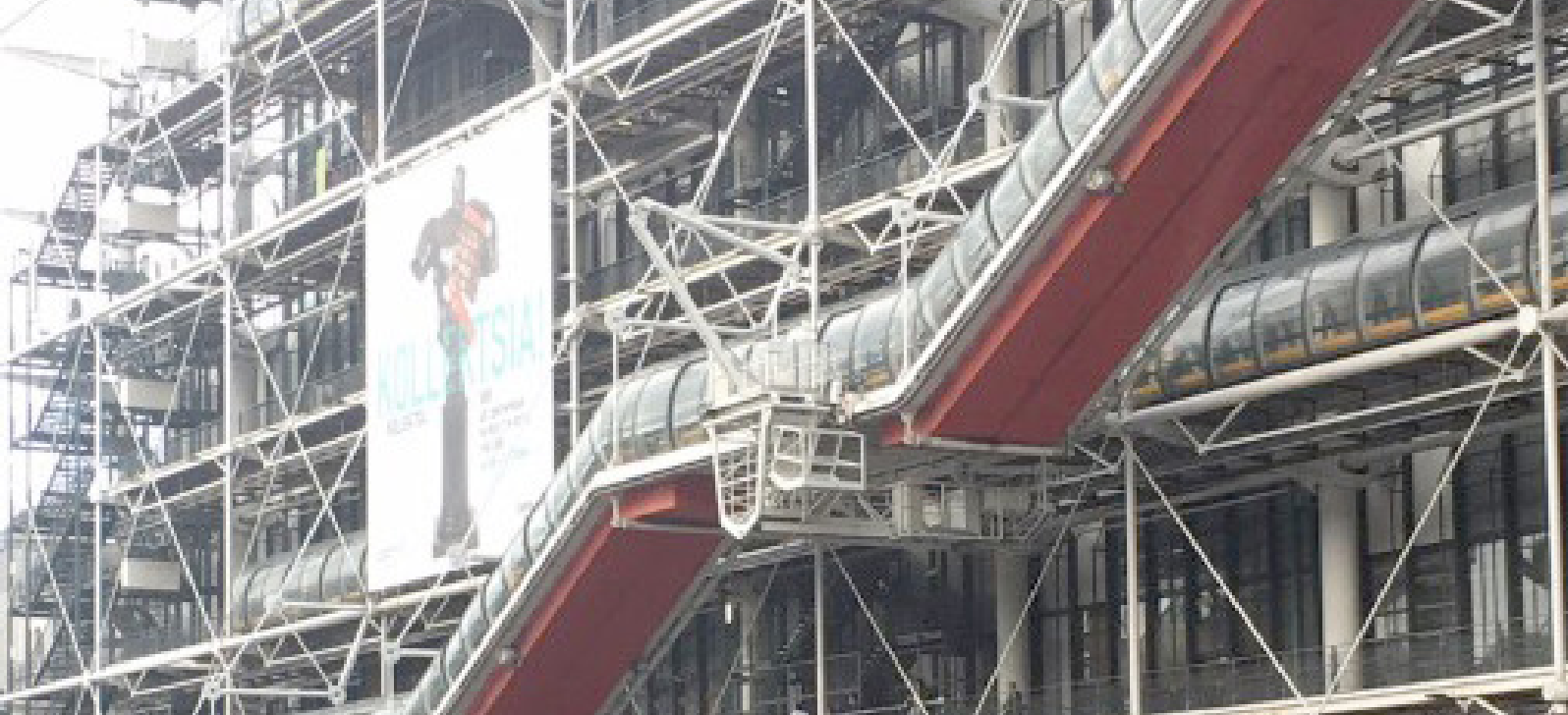

7
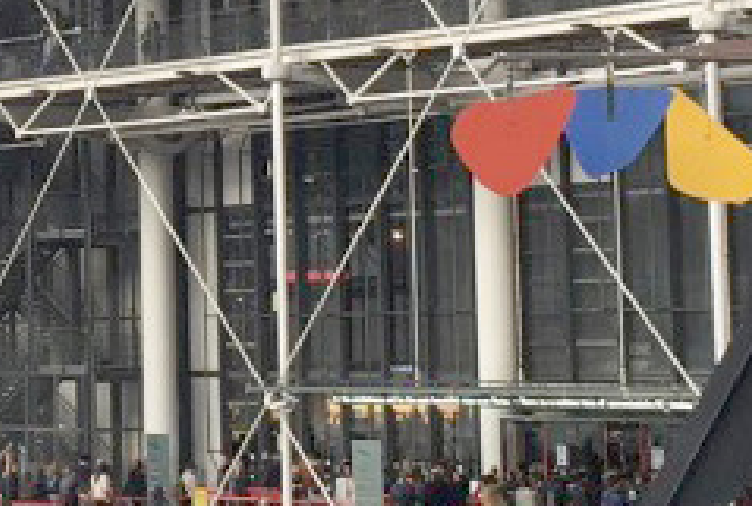

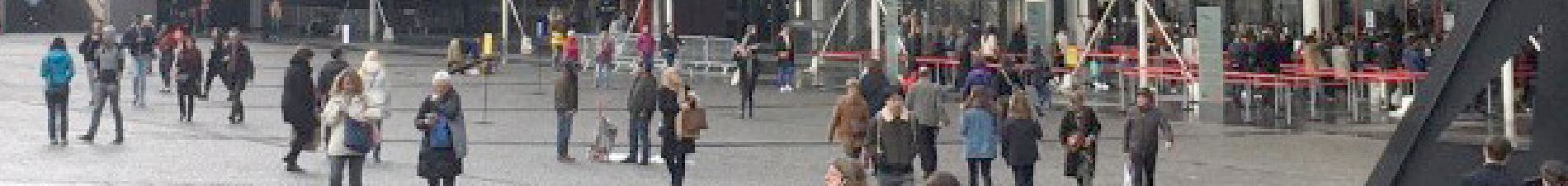

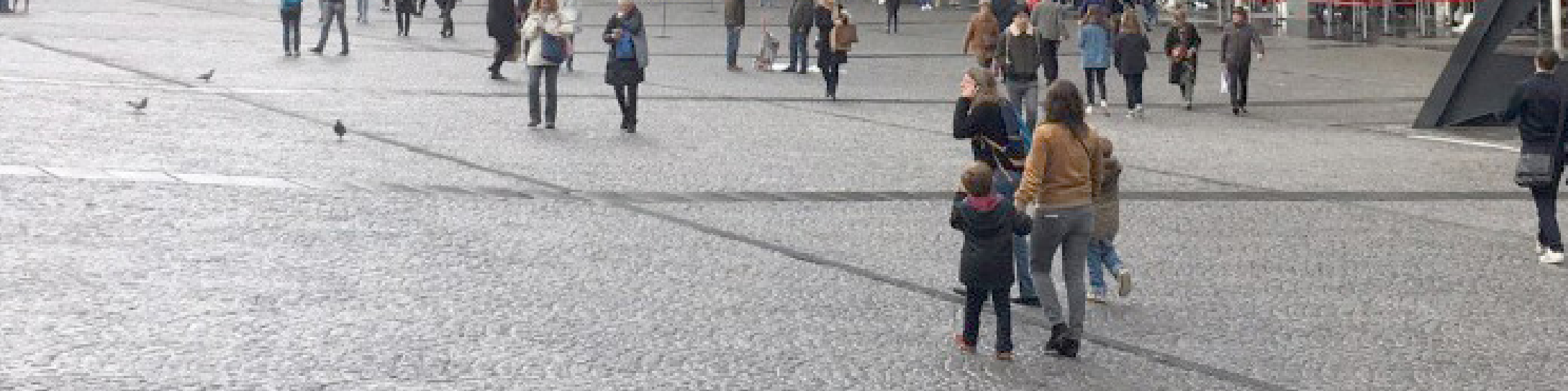

1

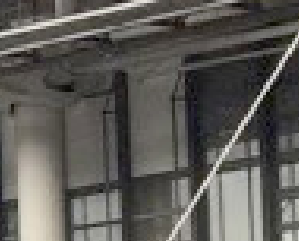




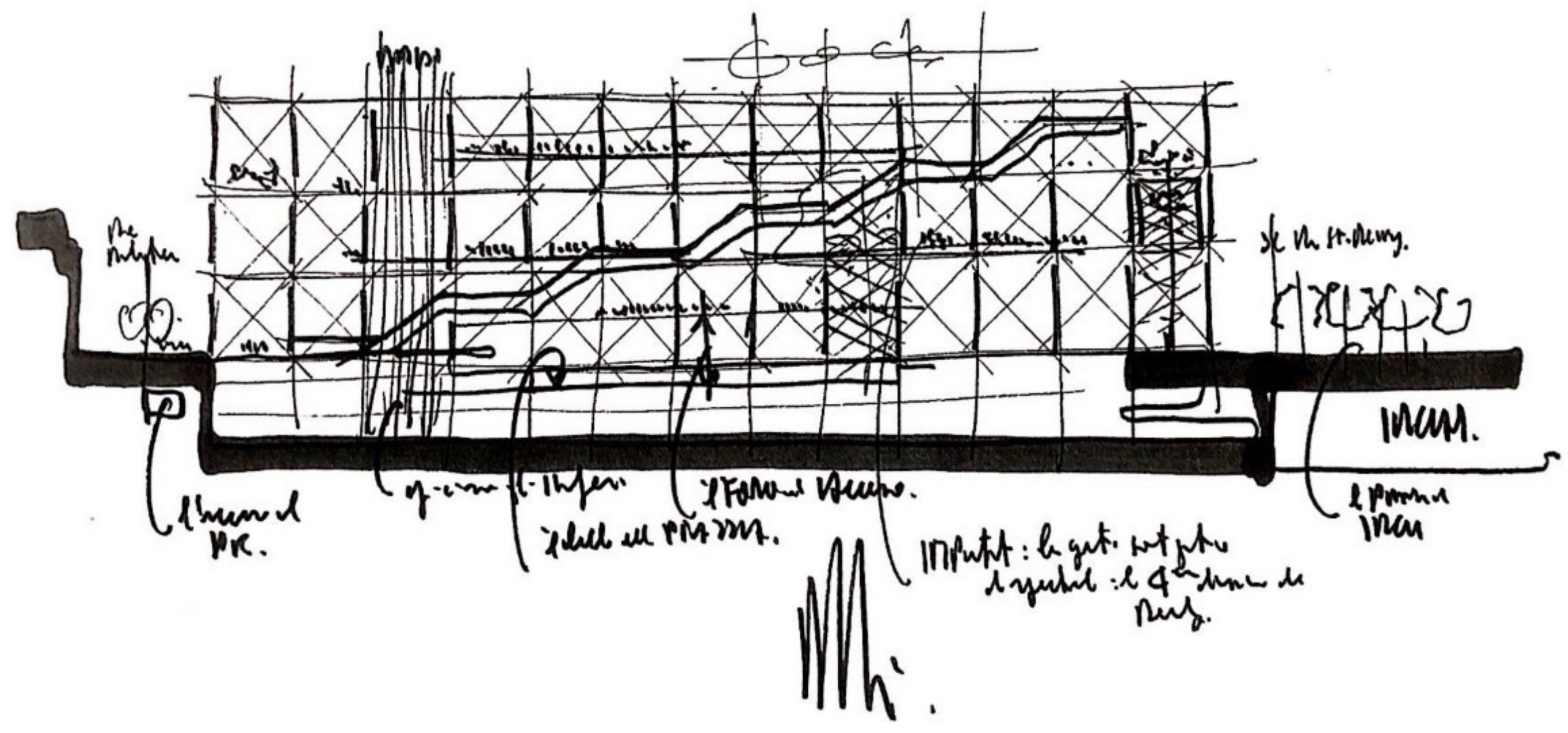

Figura 2. Boceto a mano alzada.

Fuente: Jodido (2016).

Piano tiene la creencia que el arquitecto nunca deja de trabajar en un proyecto, al ser las variables como las interacciones humanas y los escenarios donde ocurren las mismas, que son las ciudades siempre están en constante evolución. La labor del arquitecto es proponer algo nuevo, implantarlo, aunque no pueda predecir con claridad su futuro, por esta razón, el arquitecto diseñador está obligado a establecer una base sólida como punto de partida para su proyecto establecien- do determinantes profundos, éticos y clarificar sus intenciones (Camargo \& Tenorio, 2017). Las ideas de Piano y Rogers poseían cierta relación con las ideas del filósofo e ingeniero Buckminster Fuller, así como también con las de diseñadores industriales como Charles Eames, George Nelson y Víctor Papanek, y continuaron con la línea de los trabajos de Pierre Chareau, de Jean Prouvé, de Alison y Peter Smithson, y de Archigram (Domínguez, 2017). 


\section{Centro pompidou y su entorno}

El gran éxito del Pompidou según Choay (1994), es que el mismo edificio, así como sus alrededores son considerados como lugar de paso y al mismo tiempo de permanencia. Esto fue comprobado por Camargo \& Tenorio (2017) mediante una serie de entrevistas en las cuales la mayoría de las personas entrevistadas, comentaron que permanecieron en ese lugar durante un período de tiempo razonable, de igual manera la mayoría de las personas identificaron actividades pasivas y activas en los límites del sitio, y además lo disfrutaron, ya que recordaron actividades culturales, conciertos, personas interactuando y mostrando afecto y alegría. El centro Georges Pompidou está ubicado en la región central de París, a pocos de la estación de metro más grande y concurrida de la ciudad. El edificio está centralizado y extremadamente bien conectado e integrado al contexto urbano. Las vías que rodean al edificio que son las calles du Renard y Beauburg se usan intensamente, por consiguiente, el sitio es un lugar de paso a diario (Camargo \& Tenorio, 2017). El edificio solo abarca la mitad del terreno y en el resto se planificó la plaza de Beaubourg, rodeada de una secuencia de fachadas Parísinas tradicionales. De esta manera la separación del espacio público y privado es clara. $\mathrm{Al}$ acercarse al edificio se van atravesando unos espacios convexos, calles estrechas y se va encontrando con una arquitectura perteneciente a un antiguo barrio $\mathrm{Pa}$ rísino, y de repente se llega a una gran plaza, con un área de $8000 \mathrm{~m}^{2}$ (ocho mil metros cuadrados) creada para recibir visitantes y hacer la transición de escala entre diferentes edificios. Esta plaza es parte de la arquitectura del edificio, ya que es responsable de su conexión con la ciudad y los peatones. En medio de soluciones tipológicas tradicionales, Pompidou rompió paradigmas con su concepto innovador y contribuyó a una variedad de tipos de edificios en el sector. Las tipologías de los edificios colindantes varían en el tamaño de sus predios, pero en realidad los bloques de edificios son regulares, con patios internos diversificados, que permiten diferentes ocupaciones y valores. Aunque los alrededores tienen muchas aberturas, como puertas y ventanas que dan al espacio público, el edificio en sí tiene muy pocas puertas y esto no contribuye positivamente al espacio público pero la ubicación de las escaleras mecánicas panorámicas en la fachada hacia la plaza son la representación de las aberturas del edificio Pompidou al espacio público (Camargo \& Tenorio, 2017). Esto permite captar la atención del visitante al ir subiendo convirtiendo la subida en un espectáculo pero que a la vez genera una transición pública / privada bien clara.

Otro elemento que resulta exitoso en el díselo de todo el entorno y el edificio es la diferencia de nivel entre las calles locales y la plaza que da acceso al edificio ya que esos niveles están perfectamente diseñados tanto así que no se nota su presencia y hace que el espacio sea completamente accesible por el peatón. La transición es gradual, por lo que tanto el acceso a los edificios circundantes como al Beaubourg está a nivel del suelo, sin obstáculos. El resultado de esta diferencia de nivel es un conjunto de escalones que forman una tribuna, un lugar intensamente utilizado para varias actividades. 
Además, hay una estación de alquiler de bicicletas en la plaza Beaubourg y otras cinco estaciones cercanas. Los límites y el entorno del lugar ofrecen una gran variedad de actividades. Sin embargo, es visible un descenso en las actividades comer- ciales en la Rue Renard, frente a la fachada ciega del Pompidou. Las actividades y el movimiento de personas predominan en la Plaza Beaubourg, frente a la fachada principal del mismo (Camargo \& Tenorio, 2017).

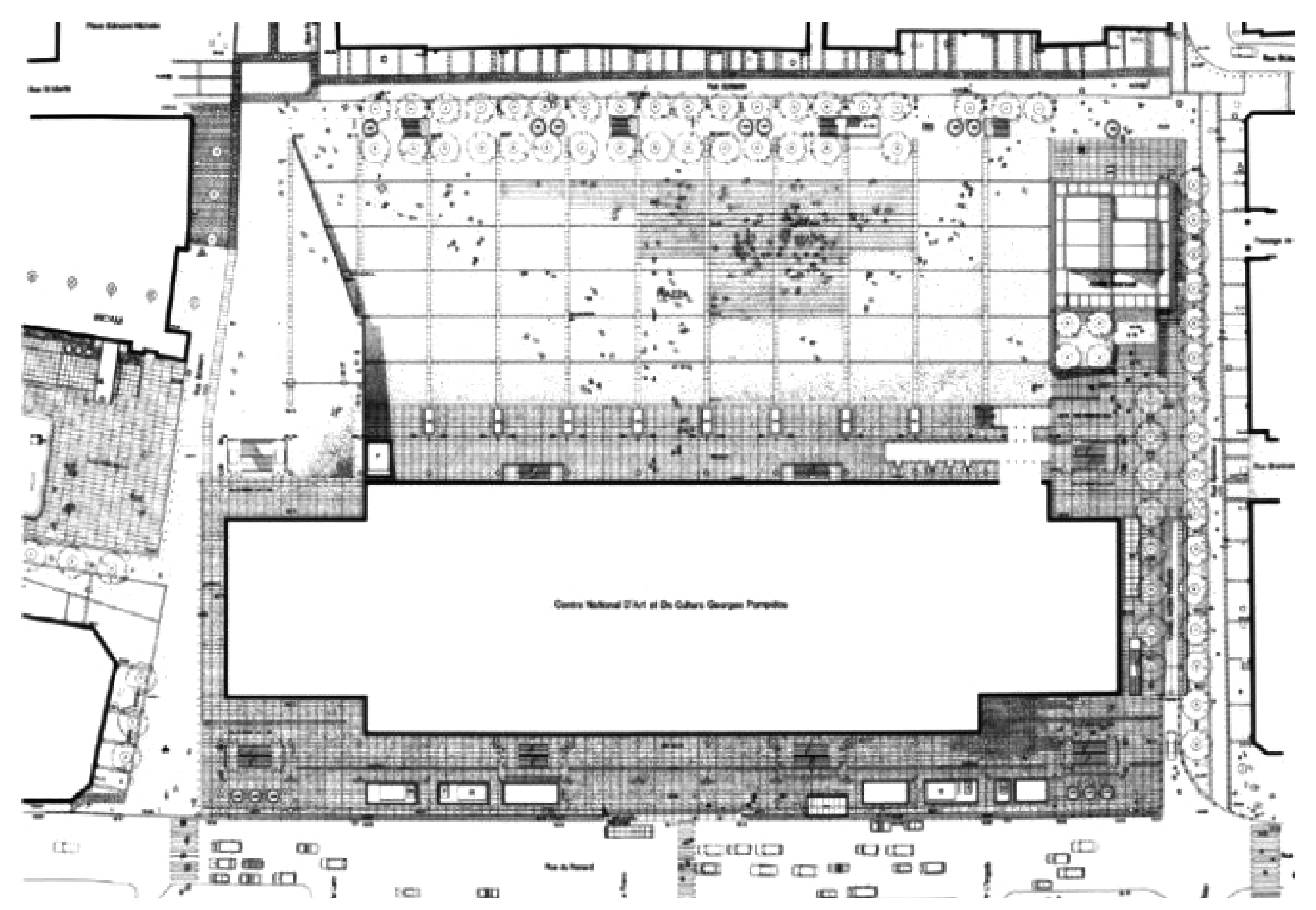

Figura 3. Implantación edificio y plaza.

Fuente: Imagen de https://proyectos4etsa.wordpress.com/2014/01/12/centro-georges-pompidou-1971-1977-richard-rogers-renzo-piano/ 


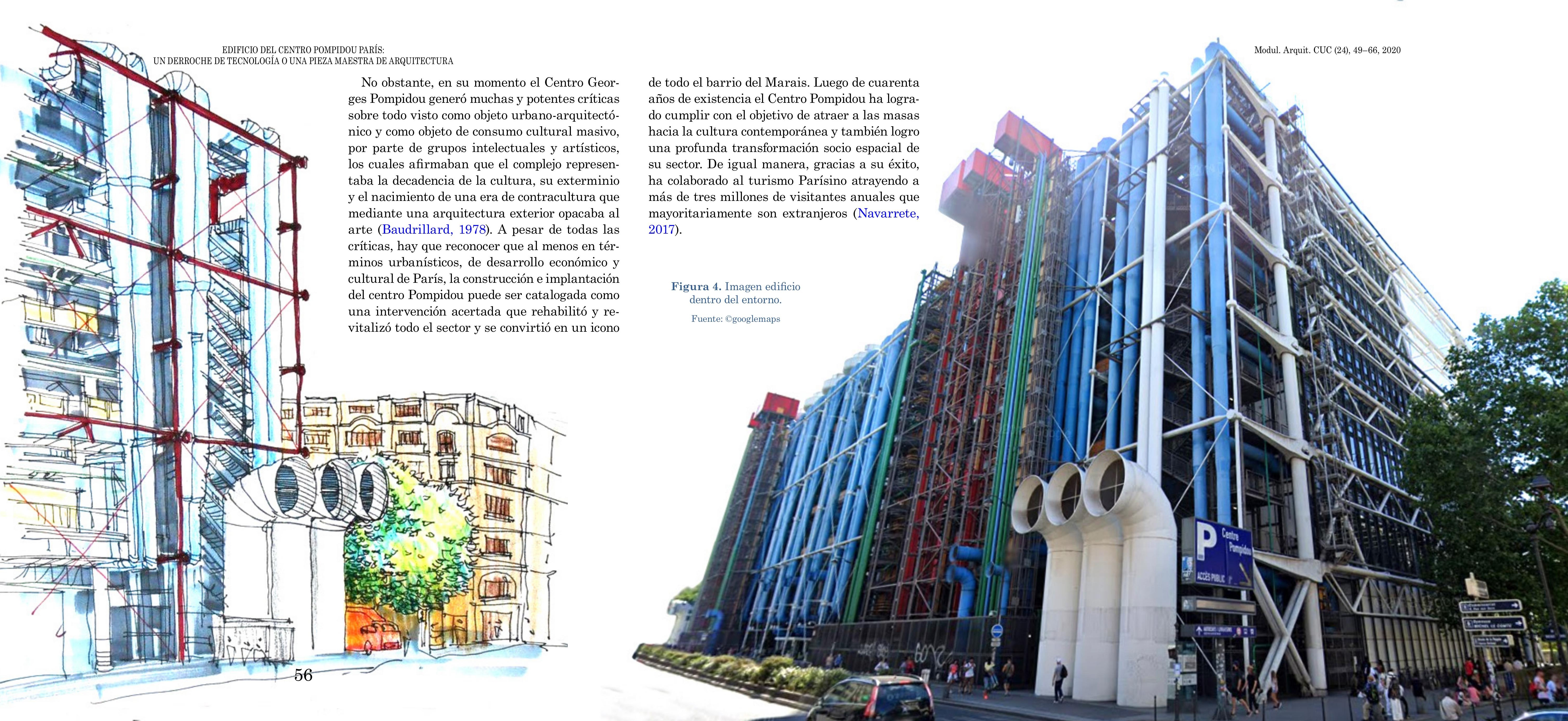




\section{Analisis de su estética}

Desde su inicio ha sido utilizado para resaltar el arte moderno y apoyar la producción artística contemporánea, ya que el mismo diseño del edificio es una obra de arte y un objeto de admiración. La estética del edificio está enmarcada por unas estructuras tubulares verticales colocadas en los lados y las rampas mecánicas de circulación en el otro extremo realzan el lenguaje tecnológico reconocido como de alta tecnología o High Tech, siendo este edificio considerado como uno de sus grandes exponentes (Murtinho, 2015). El mismo Renzo Piano, comentó que con el edificio del Centro Pompidou, lo que se había logrado era simplemente un juego con tecnología, no tecnológica (Murtinho, 2015). Otra característica estética importante, es la fachada totalmente acristalada, que permite la interacción directa con el exterior, es casi como si al interior del edificio, existiera una enorme ventana para que los visitantes puedan tener contacto visual con el exterior. Algo que va en contra del concepto más clásico de diseño de museos, con el cual los edificios de museos son opacos y se experimentan básicamente en el espacio interior de exhibición. El centro Pompidou se aleja de este concepto radicalmente y se convierte en un espacio versátil y extremadamente flexible, libre de cualquier idea historicista o formalista, aunque históricamente los edificios más innovadores y vanguardistas siempre han parecido superar su tiempo. Tal vez la característica estética más notoria es el color. El uso del color se utilizó de manera simbólica: azul para conductos de aire caliente o frío; verde para tuberías para transporte de fluidos; amarillo para instalaciones eléctricas; rojo para circulaciones, es decir, escaleras y ascensores y seguridad (Murtinho, 2015). Esto le da una imagen y carácter propio al edificio. De hecho, la paradoja del Centro Pompidou es presentar una imagen ruidosa y colorida en un entorno marcado por una arquitectura gris y constante (Murtinho, 2015). Algo como un "aquí estoy" y "aquí me quedo". De igual manera, el rasgo estructural de la utilización de acero y vidrio refuerza el concepto "de adentro hacia afuera", dándole mayor fuerza a la idea del centro cultural como una máquina. Piano una vez comparó al edificio como una nave espacial diseñada por Julio Verne (Sission, 2017). De esa manera el Centro Pompidou ha permanecido con una imagen atractiva, fácil de difundir y memorizar, fundamentada en un simbolismo mecanicista que brilla ante el público como representación de modernidad técnica (Brizotti, 2011).

Por otra parte, siempre han existido críticas a la estética del edificio, como la del teórico Kenneth Frampton, quien opina que no hay duda sobre como el derroche tecnológico utilizado no atendió la naturaleza de un centro de arte y cultura, y el concepto de flexibilidad se llevó al extremo conduciendo a la utilización de elementos desproporcionados desde el punto de vista constructivo y estructural, lo cual ocasionó la reducción del volumen del contenedor en su cantidad de plantas, obligando a construir hacia el subsuelo contiguo. Catalogó al edificio como un objeto retórico del Achigram que estaba concebido como un grupo de contradicciones variables y organizadas con el fin de obtener la máxima libertad (Hernández, 1992). 


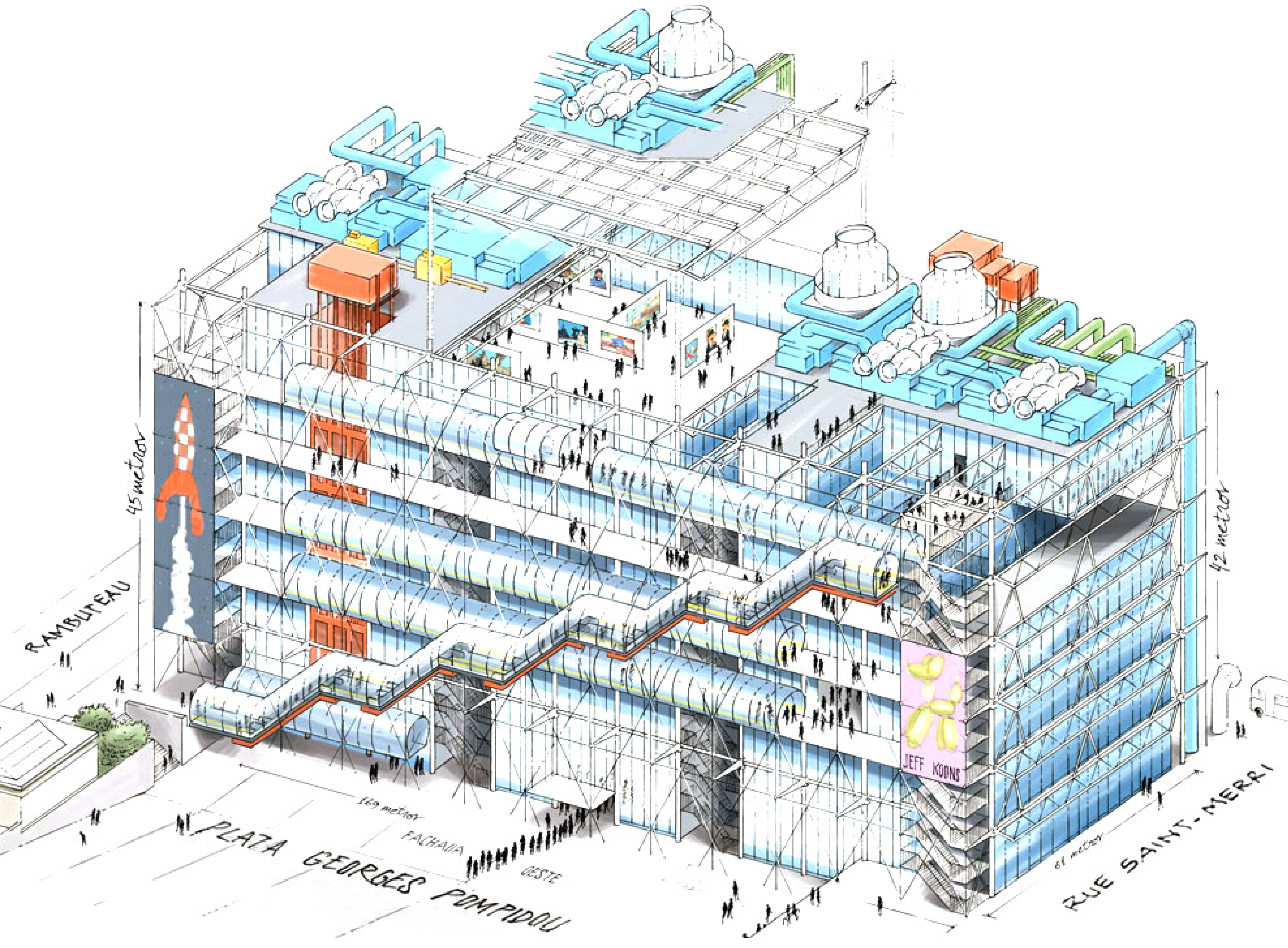

Figura 5. Infografia de Emilio Andrade (2017).

Fuente: Tomada de https://www.elmundo.es/grafico/cultu $\mathrm{ra} / 2017 / 01 / 27 / 588 \mathrm{~b} 4 \mathrm{a} 48268 \mathrm{e} 3 \mathrm{e} 2 \mathrm{c} 498 \mathrm{~b} 4675 . \mathrm{html}$ 


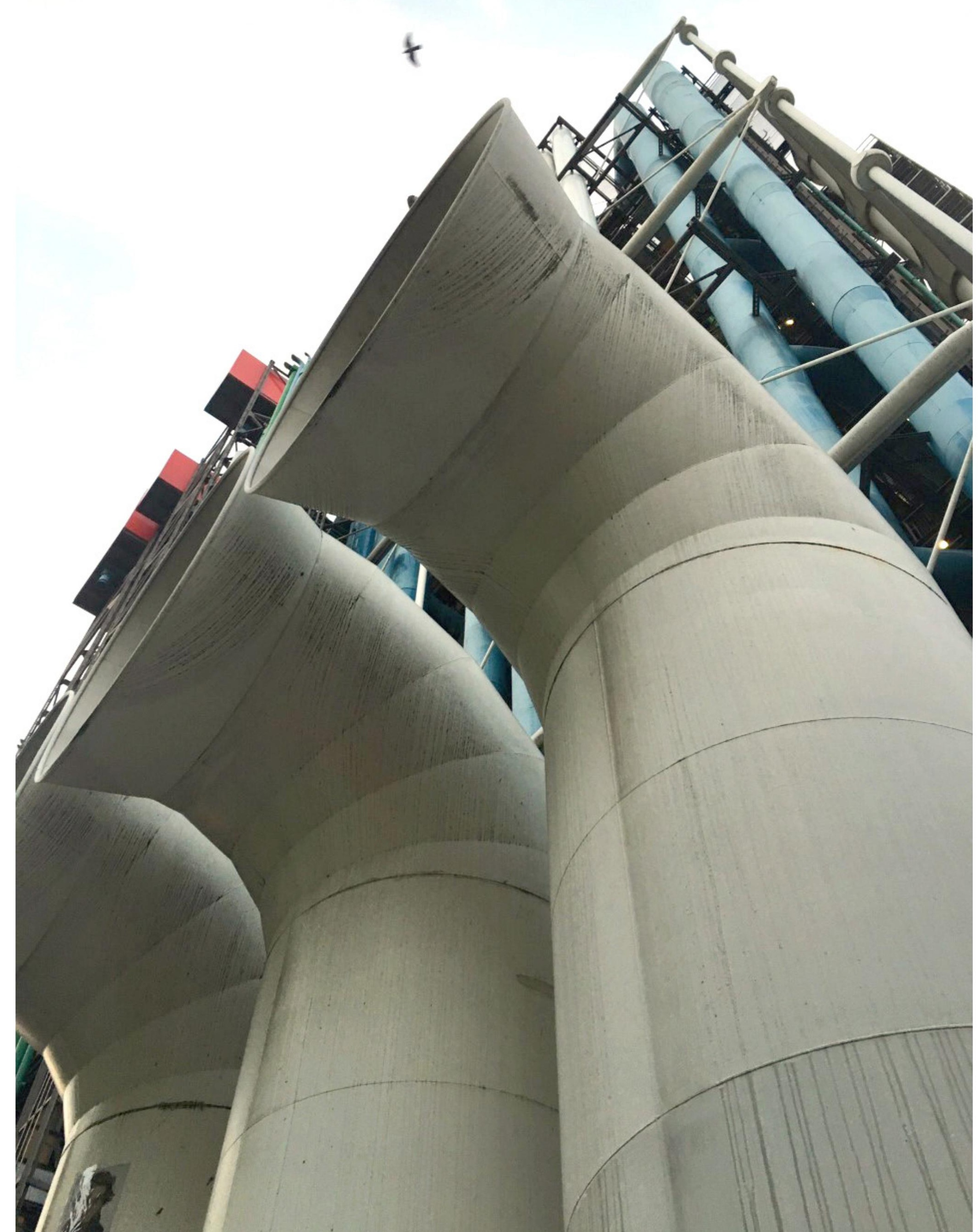

Como describe Domínguez (2017):

La imagen del Centro Pompidou fue asociada inmediatamente a la de una refinería de petróleo, y sufrió críticas crueles. Se publicó una protesta de los artistas idéntica a la que se opuso a la Fue calificado como «un burdo acto de jactancia», «una tomadura de pelo a escala monumental», o una «fanfarria patriotera realizada por una banda de pop». Sus propios autores reconocen que tuvo mucho de provocación, y que expresaba la tecnología con ironía. La incomodidad visual que producia su contrguidad con los edifcios residenestimulante e intrigante ya que era diff́cil discernir si se trataba de un edificio anti monumental o el apóstol de una nueva monumentalidad. Lo cierto es que se trata de la única obra de su tempo que compite en prestigio con las del pasado, y se encuentra en todas las historias de la arquitectura del siglo XX" (p.

\section{Sentido Especial}

El edificio de centro Georges Pompidou se penla capacidad de ser moldeado dependiendo de la necesidades de cada evento, y envuelto en un estructura tecnologica compuesta por los sistemas técnicos que sirven a ese gran espacio. En realidad, es un edifico compuesto por dos partes. La primera es una infraestructura de tres niveles donde se reagrupan los locales técnicos y de servicio. La segunda es una amplia estructura de vidrio y acero de siete niveles, incluyendo la terraza y el sotano. En este ultima parte están concentrados la mayoría de las actividades del museo. La forma rectangular de planta y el volumen permiten que los lados más largos estén dispuestos hacia la plaza permitiendo su interacción y se logra también que el interior sea bastante luminoso y todas las tuberías están a la vista y colocadas en los techos interiores, de tal manera se consigue la misma imagen industrial de caos que en las fachadas exteriores. Los arquitectos proyectaron sobre cada obra de arte un pequeño cielo raso falso para protegerla visualmente de toda la esa red de tuberías ubicada en el techo. toda la esa red de tuberias ubicada en el techo. permitiendo una una flexibilidad y una libres. ción adecuada para los visitantes (Domínguez, 2017).

La calidad espacial del proyecto es inmensa, reLa cando valores arquitectónicos específicos y pensados de esa manera. Las plantas son en realidad cinco grandes espacios sin obstáculos de 170 tros de largo por 48 metros de ancho que pule tres de largo por 4 mivididos con absoluta plexibilidad (Domínguez, 2017).

Figura 6. Centro Georges Pompidou (París, Francia Fuente: Foto Mauricio Cabas (2016) 


\section{Conclusiones}

Sin lugar a duda el Centro Pompidou sigue siendo uno de los edificios monumentos que da imagen de modernidad a la ciudad de París, no obstante, esa imagen de modernidad ya no sea la misma de hace más de 40 años, debido al rápido desarrollo tecnológico en términos de ingeniería y arquitec tura que ha dejado relevado al edificio desde el punto de vista de estético en un pasado reciente (Muñoz, 2014). La construcción del Centro Georges Pompidou, materializa de alguna forma el concepto arquitectónico del Archigram ${ }^{1}$ (utópico hasta ese momento) y lo lleva a un grado de sofisticación arquitectónica, técnica y visual nunca antes vista (Peñin, 2012). La sorpresa que generaba hace unos años no es la misma, tanto así en los años 80 fue utilizado como escenografía para películas de ciencia ficción buscando esa imagen de maquina futurista. Claro está que su implantación en todo el medio del barrio histórico de París siempre ha dado la impresión de ser un objeto extraño e inesperado o como una especie de nave interestelar parqueada en ese lugar (Muñoz, 2014). Sin embargo, esto no evita que el proyecto ostente una excelente calidad de presencia urbana y una inigualable relación con su entrono circundante integrándose de forma perfecta al tejido de la ciudad luz. La vida social que fomenta la plaza del Beaubourg demuestra que es de suma importancia la continuidad de las diversas actividades

1 Grupo creado en Londres para los años 60, enmarcado en el diseño
futurista, pro consumista einspirada en la tecnología.
Modul. Arquit. CUC (24), 49-66, 2020

y la renovación constante de la misma (Camargo \& Tenorio, 2017).

No obstante, las críticas al edificio y de cierta manera algunas debilidades de este recaen en los temas de que el Centro Pompidou carece de gesto arquitectónico y que ha fallado en proporcionar un simbolismo poderoso y que no puede estar sujeto solo a juicios estéticos (Psilopoulos, 2018). Los críticos no niegan su autenticidad ni su concepto disruptivo pero colocan en la balanza el gran costo que han generado las numerosas intervenciones arquitectónicas al las que ha tenido que ser sujeto el edificio. Las dificultades que se han tenido que resolver sobre la marcha debido a lo obsoleto de los equipos de redes de servicio instalados y otros sistemas sin poder alterar la estética y la plástica del complejo expone con amplia claridad la falta de flexibilidad técnica y lo cual era una de las premisas del diseño dinámico. La concepción plástica y estética se convirtió en una camisa de fuerza, llevando a al convirtió en una camisa de fuerza, 1 era e ideolócico (Hernández, 1992). Tanto así que la arquitectura se podŕa tranfor Tan as que la medio para molo un la cultura. Un producto de moludo (Porto, 2005)

Figura 7. Centro Georges Pompidou (París, Francia) Fuente: Foto Mauricio Cabas (2016). 


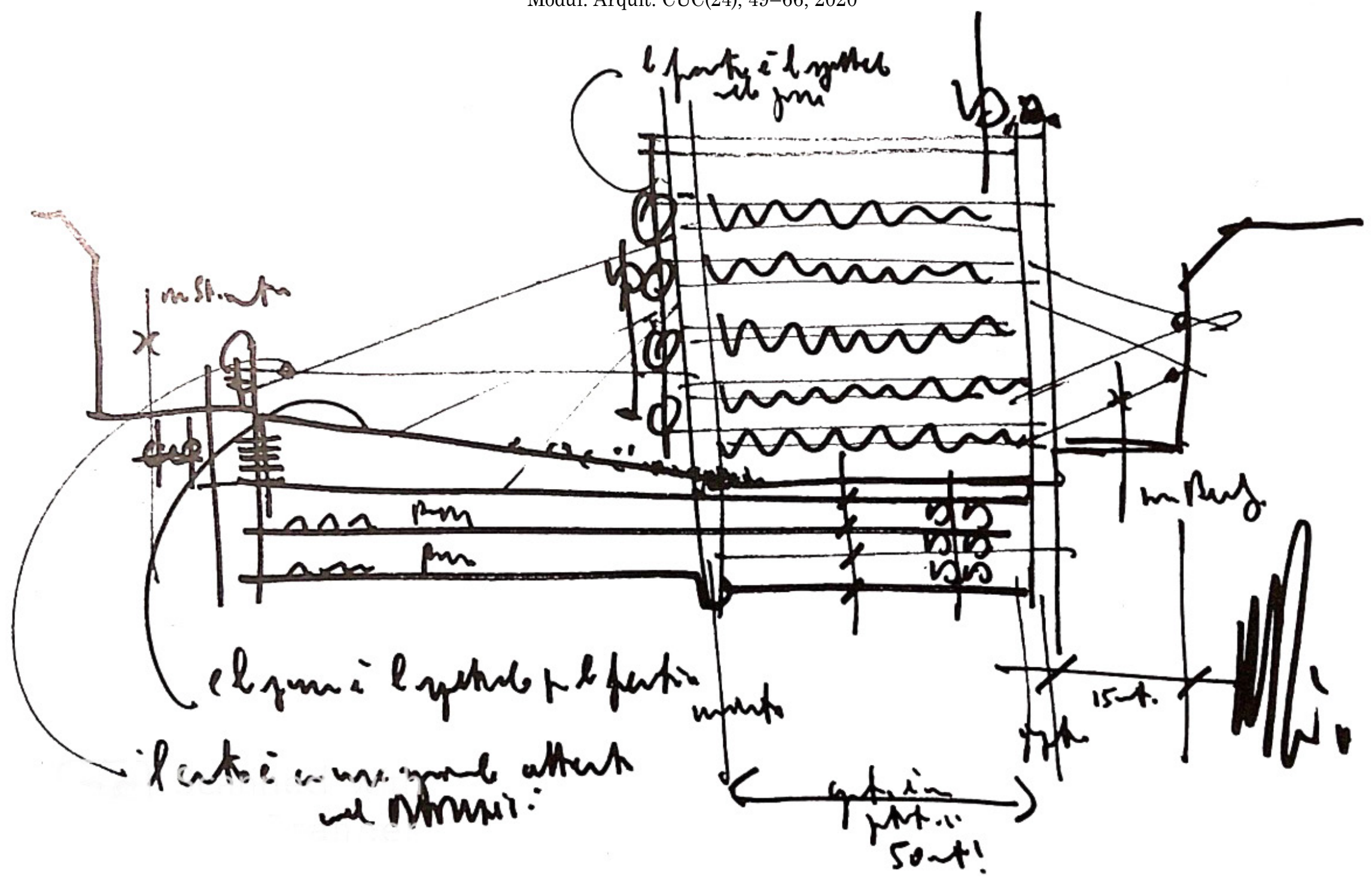

Figura 8. Boceto a Mano alzada.

Fuente: Jodido (2016).

Autores como Baudillard ${ }^{2}$ denunciaban que el Beaubourg (como también se le conoce al Centro Georges Pompidou) era un simple supermercado de arte y solo era un elemento que pretendía simular una esencia de cultura (Muñoz, 2014).

2 Jean Baudillard Reims (27 de julio de 1929- 6 de marzo de 2007). fue un Filósofo y sociólogo francés, crítico de la cultura francesa. Su trabajo de basaba en el análisis de la posmodernidad.
Aunque desde cierto punto de vista esto no es tan malo como se suponía y dio lugar a que la misma arquitectura le quitara protagonismo al arte que dentro se exhibía. Con el Pompidou se hizo visible una nueva forma de exhibir espacios, yendo en contra del posmodernismo y logrando un renacer del concepto individualista a finales de los años 60 (Porto, 2005). 
Hernández, R. (1992). Centro Georges Pompidou 1992. 20 años de ilusión. RE, Revista de Edificación, 12, 61-64. Disponible en http://hdl.handle.net/10171/16510

Jodidio, P. (2016). Renzo Piano Building Workshop. La poesia al vuelo. Colonia: Taschen.

Moruno, L. (2019). Arquitectura y maquinas de movimiento para el nuevo siglo: Renzo Piano en espacio-evento. N20, Proyecto Progreso Arquitectura, (20), 120-139. http://dx.doi.org/10.12795/ppa.2019.i20.07

Muñoz, O. (2014). El Centro Pompidou, sin titulo. Teatro Marittimo, (14), 27-37.

Murtinho, V. (2015). Centro Pompidou: um espetaculo de luz, cor e aco. Metalica, (40), 18-29.

Navarrete, D. (2017). Museos y urbanismo en la ciudad turistica: Centro Pompidou, Quai Branly y Fundacion Louis Vuittonen París como casos de estudio. Arte y ciudad, (11), 157-184.

Peñin, A. (2011). "Mas gruseo que el papel". Investigacion y procesos de realización. En, 4IAU, $4^{\text {a }}$ Jornadas Internacionales sobre Investigación en Arquitectura y Urbanismo, Valencia, España. Disponible en http://hdl.handle.net/10251/15012

Porto, F. (2005). The Pompidou Centre: or the hidden kernel of desmaterialisation. The Journal of Architecture, 10(5), 573-589. https://doi. org/10.1080/13602360500463156
Psilopoulos, A. (2018). "Le geste architctural" Symbolism and authority in the case of Centre Beaubourg. Architecture_MPS, 13(1), 1-30. https://doi. org/10.14324/111.444.amps.2018v13i1.001

Sainz, J. (1990). El oficio mas bello del mundo. Renzo Piano y la pasion por construir. Monografias de Arquitectura y Vivienda, (3), $4-5$.

Sission, P. (january 23, 2017). Centre Pompidou, a monument to modernity: 8 things you didn't know. A new book explores the secrets of this revolutionary building. Available from: https://www.curbed.com/ platform/amp/2017/1/23/14365014/centrepompidou-París-museum-renzo-piano-richard-rogers 